\title{
Obituaries
}

\section{George Warburton Ashcroft}

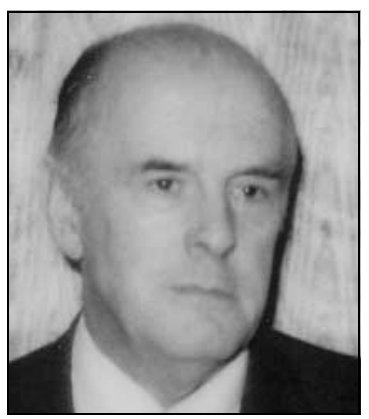

Formerly Director, Medical

Research Council Brain Metabolism Unit, Edinburgh, and Professor of Mental Health, University of Aberdeen

George W. Ashcroft was born in 1930 in Bolton, Lancashire. He began his training in psychiatry in 1957 at the Royal Edinburgh Hospital following his military service and a few years' practice of obstetrics and gynaecology. In 1959 he was awarded a Medical Research Council (MRC) Clinical Research Training Fellowship to work in Edinburgh and Cambridge on cerebral amine metabolism under the supervision of Dr Martha Vogt and the brilliant methodologist Dr Tom Crawford. He continued his research with a Mental Health Research Fund Senior Fellowship (1962-1965) and was appointed Clinical Scientist in what later became the MRC Brain Metabolism Unit within the Pharmacology Department of Edinburgh University. In 1970 he was appointed as the Unit's Director. It is important to note that at the time it was not established that serotonin is a neurotransmitter with a metabolism that could be of importance in mental health. Cerebrospinal fluid studies suggested that there was a problem in the production of 5-HT in depressive disorder. George's demonstration that the turnover of 5-HT was greatly increased by the administration of I-tryptophan inspired a new therapy using this amino acid either alone or combined with other drugs, such as phenelzine and lithium, in severe depressive disorder. These treatments frequently produced dramatic improvement in patients with chronic treatment-resistant depression.

George's achievements were rewarded in 1976 with a Fellowship of the Royal Society of Edinburgh and, in 1978, with the appointment to the Chair of Mental Health at the University of Aberdeen. He secured Wellcome funding to attract John Besson to Aberdeen, initiating a pioneering imaging programme in collaboration with John Mallard's world-leading Department of Medical Physics. He attracted international research fellows, such as Roger Makanjuola (professor of psychiatry in Ile-lfe, Nigeria) and Tomás Palomo (professor of psychiatry in Madrid, Spain), to continue their pharmacological research in Aberdeen. Above all, he encouraged a number of junior psychiatrists to acquire scientific knowledge and skills and trained them clinically to become a cohort for the next generation of chairs of psychiatry in Aberdeen, Dundee, Edinburgh, Newcastle and Oxford. Importantly, he also trained a cohort of clinicians, psychiatrists and general practitioners (GPs), who now populate and energise many clinical centres in the country.

As a psychiatrist, George represented a brand of therapeutic optimism, which, in other words, insisted that no patient was untreatable. In the presence of personality disorder, some of which would have been classed as 'borderline', he continued with his own pragmatic brand of psychotherapy. He made himself available as a lifeline to many disturbed patients who could phone him from any part of the country, often at inconvenient hours, providing a shining example of not-so-new ways of working.

As a research worker, as a psychiatrist, and as a man he had an inquisitive intelligence which was not satisfied until he found solutions. He could be a fount bubbling over with fresh ideas for any of his staff who asked for research advice. His suggestions were mainly derived from basic psychopharmacology to be translated into clinical and practical applications, long before the invention of translational medicine. But above all he was a friendly and compassionate man; the interest of others formed the source of his well-being. He was a family man, with a daughter and three sons, whom he supported in a caring but unobtrusive way. When asked what gave him the most satisfaction in his career he would say that it was his professional involvement with patients, from whom he had learnt more than he ever did from his professional colleagues. Nevertheless, he would show unstinting loyalty and support to his colleagues, allowing them to weather the unavoidable rejection and frustration that comes with academic practice, and persevere until successful.

He was bemused by the heavy-handed management style that became popular during the Thatcher years. In Aberdeen he assumed clinical sector responsibility for Gordon District, which he transformed into an exemplary service. Already in the 1980s community psychiatry flourished at the local GP practices in Inverurie and Ellon, in joint ward rounds in Inverurie Community Hospital and through close liaison with the local authority social work departments. George established a GP-run multidisciplinary dementia assessment unit in Inverurie that now carries his name. He continued to make active contributions to self-help groups after his retirement, running groups for young people with diabetes, older patients and their relatives.

During his tenure in Aberdeen, undergraduate teaching and examination were re-designed, emphasising clinical bedside experience and forcing students to engage with patients by making a one-hour clinical examination the centrepiece of the psychiatry degree examination. Students had to examine the (real) patient for 40 minutes in front of the two examiners, who then proceeded to take a 20-minute viva both on the clinical examination and issues such as further assessment, differential diagnosis and management. The employment of actors, now a regular practice in undergraduate and even in postgraduate membership examinations, would have been anathema to him.

Above all, his enthusiasm, sense of humour and integrity have helped his junior colleagues to survive the current wave of de-professionalisation that has arrived with such symptoms as New Ways of Working, appraisal by the hand of administrators, and criminal records checking. He would have been too optimistic and too tactful to point out that if we do not assume this integrity a priori and foster it in all fellow professionals, we fully deserve the second-rate cookbook medicine full of naive micro-checks, doublespeak and jargon that is on the menu today.

Donald Eccleston and Klaus Ebmeier 